\title{
OPEN Dramatic nucleolar dispersion in the salivary gland of Schwenkfeldina sp. (Diptera: Sciaridae)
}

\author{
José Mariano Amabis \& Eduardo Gorab (i) ${ }^{凶}$
}

Micronucleoli are among the structures composing the peculiar scenario of the nucleolus in salivary gland nuclei of dipterans representative of Sciaridae. Micronucleolar bodies contain ribosomal DNA and RNA, are transcriptionally active and may appear free in the nucleoplasm or associated with specific chromosome regions in salivary gland nuclei. This report deals with an extreme case of nucleolar fragmentation/dispersion detected in the salivary gland of Schwenkfeldina sp. Such a phenomenon in this species was found to be restricted to cell types undergoing polyteny and seems to be differentially controlled according to the cell type. Furthermore, transcriptional activity was detected in virtually all the micronucleolar bodies generated in the salivary gland. The relative proportion of the rDNA in polytene and diploid tissues showed that rDNA under-replication did not occur in polytene nuclei suggesting that the nucleolar and concomitant rDNA dispersion in Schwenkfeldina sp. may reflect a previously hypothesised process in order to counterbalance the rDNA loss due to the under-replication. The chromosomal distribution of epigenetic markers for the heterochromatin agreed with early cytological observations in this species suggesting that heterochromatin is spread throughout the chromosome length of Schwenkfeldina sp. A comparison made with results from another sciarid species argues for a role played by the heterochromatin in the establishment of the rDNA topology in polytene nuclei of Sciaridae.

Transcriptional activity of ribosomal RNA (rRNA) genes in specific chromosome regions is the primary event for the local assembly of the nucleolus, the starting site of ribosome biogenesis. Light microscopy enables to observe such a nuclear entity in most cells but the optimal, detailed nucleolar visualisation under the same optical device is found in salivary gland cells of dipterans, one of the cell types where giant, polytene chromosomes develop. These chromosomes, that are an exceptional case of the cell cycle, are formed from chromosomes of diploid nuclei by duplication rounds of chromatids. At the end of each S-phase, DNA strands do not segregate, remaining paired and parallel to each other. Cell division does no occur as polytene cells do not enter mitosis, so that they remain in interphase. Among other features shared by polytene chromosomes, DNA under-replication is of particular interest in relation to this report. Such a phenomenon is usually found in heterochromatic regions and results from partial sequence replication as a possible consequence of stalled replication forks. Stalled forks are structurally unstable and are apt to collapse leading to DNA breakage and loss ${ }^{1}$.

Among Diptera, Sub-Order Nematocera, representatives of Sciaridae constitute a morphologically peculiar and unusual example of nucleolus as observed in salivary gland nuclei of species within this family.

Early findings in several sciarid species showed the nucleolus at the pericentric end of the X chromosome in polytene cells $s^{2-6}$. However, the sciarid nucleolus tends to fragment throughout the larval development so that, in contrast to well formed nucleoli from dipterans such as Drosophila ${ }^{7}$ and chironomid species ${ }^{8}$, a prominent nucleolus is not seen in the salivary gland nuclei of Sciaridae. Another type of nucleolar material named micronucleoli also occurs in the sciarid salivary gland. These structures containing DNA and RNA appear as small, round bodies scattered in the nucleoplasm and can be associated with certain chromosome regions ${ }^{5,9-11}$.

The development of the in situ hybridisation method at the end of the decade of 1960 allowed the identification of chromosomal regions containing rRNA genes, or ribosomal DNA (rDNA), and produced the first results in sciarid species. In Sciara coprophila, radioactively labelled rRNA probes hybridised to the heterochromatic end of chromosome $\mathrm{X}$ and to micronucleoli ${ }^{12-15}$. In Rhynchosciara hollaenderi, heterochromatic ends of chromosomes 

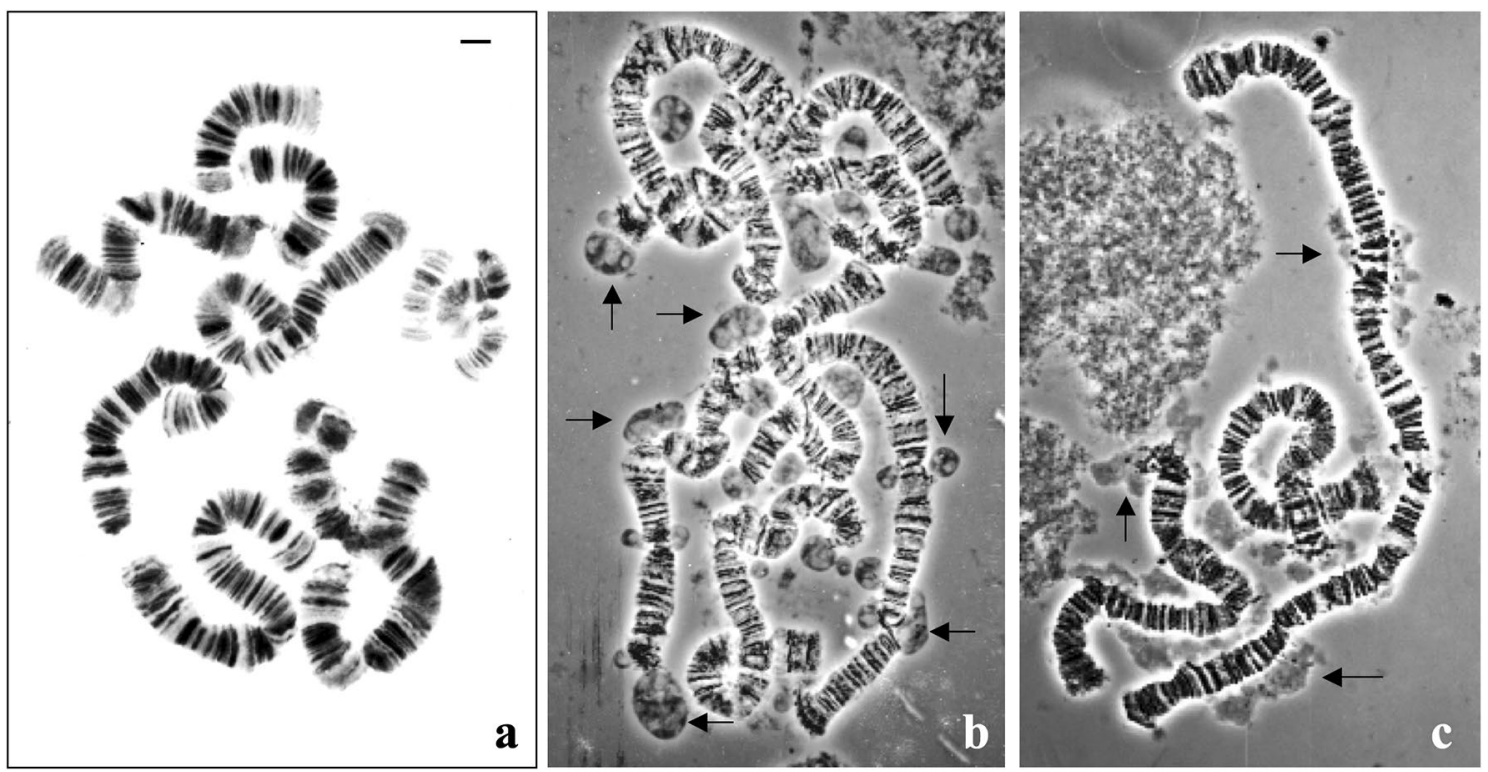

Figure 1. (a-c) Polytene chromosomes of Schwenkfeldina sp. (a) Orcein staining photographed under bright field allows chromosome visualisation but not extrachromosomal structures of interest to this work. (b,c) Phase contrast images showing two morphological aspects often observed in the nuclear entities of this species. The arrows point to some examples of structures, either disconnected or attached to the chromosomes, that were eventually identified as micronucleoli on the basis of in situ hybridisation results. (b) Nucleolar bodies displaying sharp edges and exhibiting some internal structure and (c) micronucleoli with less sharp edges and apparently devoid of internal structure. Bar $=15 \mu \mathrm{m}$.

$\mathrm{X}$ and $\mathrm{C}$ hybridised consistently to rRNA. In this species, hybridisation to specific regions of chromosomes $\mathrm{A}$ and $\mathrm{B}$ appeared to be dependent on the presence of micronucleoli attached to those chromosomal sites ${ }^{12}$. Early data in Rhynchosciara americana chromosomes ${ }^{16}$ showed the rDNA localisation similar to its closely related species, $R$. hollaenderi.

Later, non-isotopic in situ hybridisation applied to $R$. americana showed in addition an rDNA site at the non-centromeric end of the X chromosome ${ }^{17-19}$. In Rhynchosciara baschanti rRNA genes are mainly located in the proximal end of the X chromosome. However, evidence for rDNA sites in the three polytene autosomes of the latter species was also presented ${ }^{20}$. In Trichomegalosphys pubescens (formerly named Trichosia pubescens), the rDNA is localised in the heterochromatin of the $\mathrm{X}$ chromosome and in free micronucleoli ${ }^{18,21}$ namely the same pattern described previously for S. coprophila. In relation to all sciarid flies studied with nucleolar focus, a very short account on the rDNA localisation in Schwenkfeldina sp. showed an unusually high number of rDNA hybridisation sites associated to the salivary gland chromosomes. In contrast, non-polytene chromosomes display the nucleolar organiser region (NOR) in a single locus, a feature shared by other sciarid species ${ }^{18}$.

While research on sciarid NORs has long been initiated, structural peculiarities restricted to this dipteran family have remained obscure. In particular, multiple NOR sites detected by rDNA probes in the salivary gland, in contrast to a single location in mitotic chromosomes. Also, variable chromosomal locations of NORs in the salivary gland of sciarid species that have been studied, some of which closely related, are intriguing and deserved a more detailed investigation in this work. Schwenkfeldina sp. was chosen to be studied in this report because of its unique, unexpected degree of nucleolar fragmentation and dispersion, detected by in situ hybridisation, compared to any other sciarid species that have been studied with a nucleolar focus. We thought that this extreme case of nucleolar dispersion could help to identify genomic features or even some functional link implied in the exceptional nucleolar pattern in terms of localisation in the Schwenkfeldina salivary gland, which was described shortly in a previous work ${ }^{18}$.

In order to better understand such an unusual picture in this species, chromosomal localisation of the rDNA in distinct cell types, its relative proportion in polyene and diploid cells as well as epigenetic markers were assessed in this fly. Also, a comparison of Schwenkfeldina results with those from another sciarid fly, Rhynchosciara americana, take part in this work. The data suggest that rDNA dispersion is dependent on polytenisation and chromosomal localisation of the heterochromatin in the species analysed. Support for rDNA dispersion as a device to restore the rDNA loss due to under-replication in Schwenkfeldina is also provided.

\section{Results}

Early cytological observations on Schwenkfeldina salivary gland chromosomes. Polytene chromosomes of Schwenkfeldina sp. commonly display several breakpoints that sometimes make difficult a rapid identification of its basic chromosome number (Fig. 1a). However, the frequency of connections between chromosome fragments as well as observations on mitotic chromosomes showed that this species has a basic chromosome number of four (Fig. 1a, Fig. S1, Fig. S3, Fig. S11). In contrast to the other sciarid species that have 

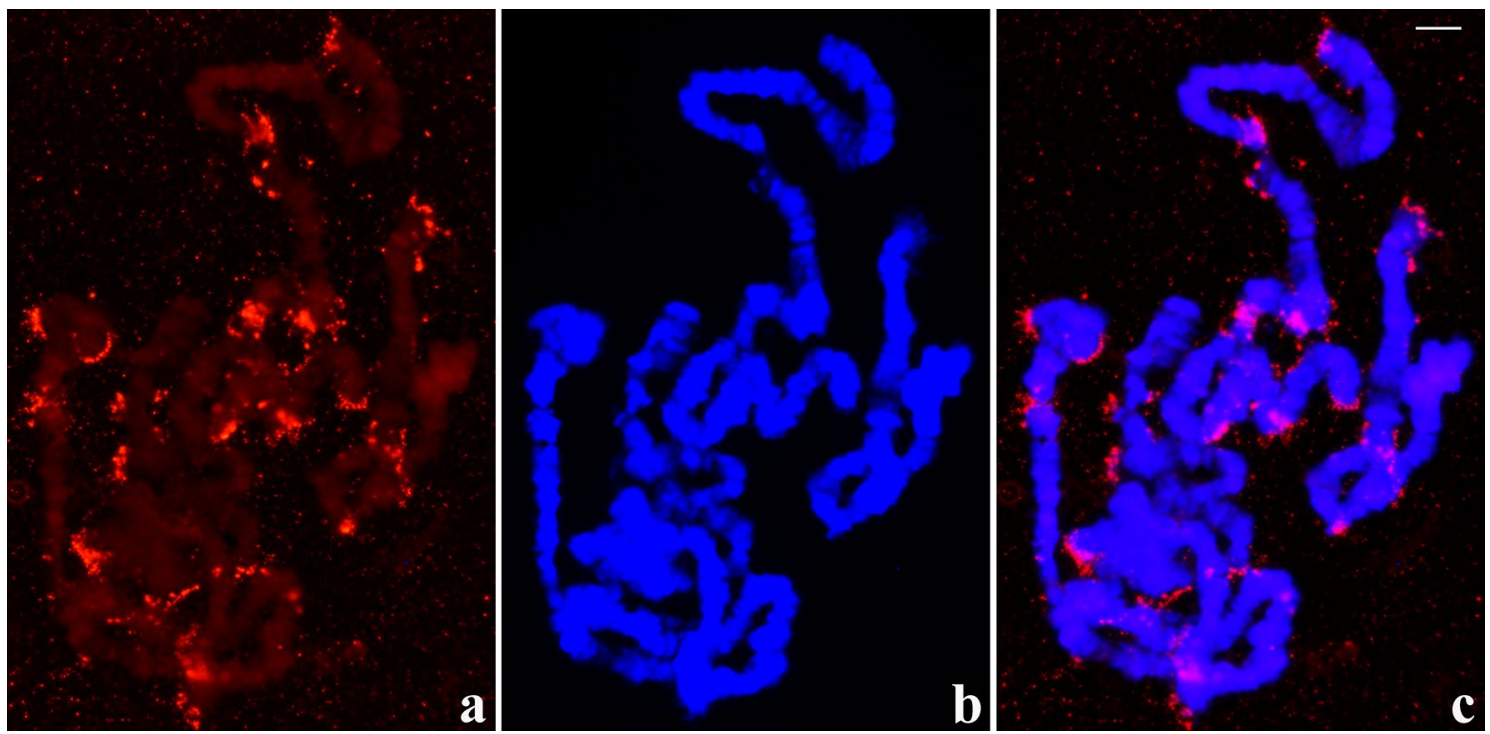

Figure 2. (a-c) Localisation of the rDNA in Schwenkfeldina sp. polytene chromosomes of the salivary gland showing significant rDNA dispersion as visualised by RNA probe signals (a), its corresponding DAPI staining image (b) and the merged signals (c) either disconnected or attached to the chromosomes. Bar $=45 \mu \mathrm{m}$.

been studied, nucleolar-like material in the Schwenkfeldina salivary gland is not primarily associated with one particular chromosome (Fig. 1b,c). As Schwenkfeldina sp. larval groups used for slide preparation reached the adult stage, the nucleolar dispersion is not a consequence of abnormal larval development. Micronucleolar-like bodies appeared associated with several regions of the four polytene chromosomes and sometimes were also dispersed in the nucleoplasm, apparently disconnected from the chromosomes. Their morphology was not the same as that observed in Sciara, Rhynchosciara and Trichomegalosphys salivary glands in the sense that they were larger than those of the latter species. In addition, nucleolar bodies of Schwenkfeldina sp. sometimes display an apparent internal structure (Fig. 1b) while other situations show instead amorphous appearance (Fig. 1c). After examining fourteen slides, it was observed that the association of micronucleoli-like structures with chromosomal regions does not occur by chance. Chromosome termini, breakpoints and certain interstitial regions of a given chromosome appear recurrently associated with nucleolar-like bodies (Fig. S1).

rDNA localisation features in the salivary gland of Schwenkfeldina. As already observed in several sciarid species, the salivary gland is a long organ and winds up the body of the larva. Salivary gland cells placed in its anterior part undergo more DNA replication cycles than those composing posterior regions of the gland. Consequently, polytene chromosomes from the anterior part attain the highest polyteny degree. In situ hybridisation applied to these chromosomes usually shows significant rDNA dispersion. The most frequent pattern consists of rDNA probe signals at chromosome ends as well as attached to several interstitial sites, mostly chromosome breakpoints. Usually, no chromosomal site displaying a stronger hybridisation signal than other sites is detected, namely no main NOR was found (Fig. 2). In much less frequent cases, hybridisation signals expand to larger areas when compared to usual situations suggesting decondensation of the structures containing rDNA that are attached to chromosome regions (Fig. S2). The results of in situ hybridisation were reproduced many times and made possible a compilation of the most frequent chromosomal regions to which micronucleoli is attached (Fig. S3).

Regarding sciarid salivary glands, they are usually composed of three cell types (S1, S2 and S3) that are grouped into sections throughout the salivary gland length. Anterior cells (S1) always exhibit chromosomes that have the highest polyteny degree. Chromosomes in posterior cells of the salivary gland (S2 and S3) display variable, lower polyteny degree and this provided additional information on the nucleolar fragmentation in Schwenkfeldina sp. For example, some polytene chromosomes whose polyteny degree is comparatively high (S2) but still lower than those from the anterior cells (S1) may exhibit significant rDNA dispersion so that a principal (NOR) is not visualised (Fig. 3). In contrast, polytene chromosomes from posterior cells showing very low polyteny degree (S3) enabled the identification of a main NOR site thanks to the intensity of its hybridisation signal. In addition, signs of rDNA dispersion probably from the main rDNA region were also detected (Fig. S4).

Transcriptional activity of nucleolar bodies. The localisation of the rDNA in polytene chromosomes of this species raised the question whether ribosomal gene transcription is also spread in the nucleus or restricted to a micronucleoli subset. To address this issue, the procedure for the detection of endogenous RNA.DNA hybrids was used, namely the formation in situ of hybrid molecules composed of template DNA and the product of its own transcriptional activity ${ }^{22-24}$. Although, as for in situ hybridisation, use of this technique may lead to a considerable loss of nucleolar morphology, RNA.DNA hybrids were detected on entire regions coinciding with the presence of micronucleoli (Fig. 4). The reproduction of the method showed hybrid detection in the whole micronucleolar set and, in some slides, the hybrid signal occupied partially the micronucleolar area (Fig. S5). 

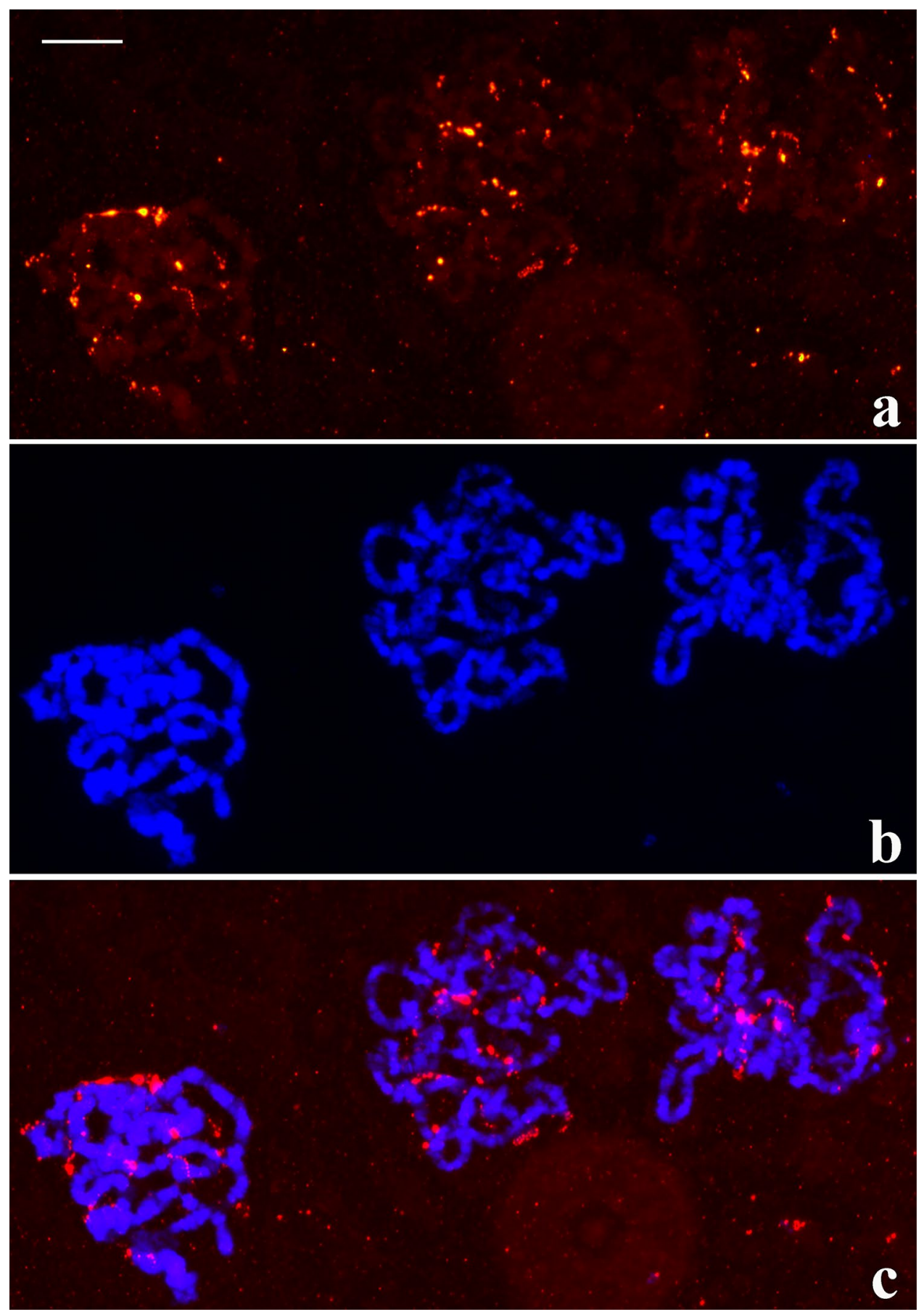

Figure 3. (a-c) Localisation of the rDNA in Schwenkfeldina sp. polytene chromosomes from posterior cells of the salivary gland showing rDNA dispersion at a lesser extent than nuclei from anterior cells as inferred by RNA probe signals (a), its corresponding DAPI staining image (b) and the merged signals (c). Bar $=65 \mu \mathrm{m}$.

Controls performed with slides previously treated with RNAse A or RNase A/H showed no chromosomal labelling after completion of DNA.RNA hybrid detection method.

rDNA localisation in Malpighian Tubules, neuroblasts and embryonic nuclei. Usually, low polyteny is a feature of chromosomes in Malpighian Tubules of Diptera. In situ hybridisation results from several slides showed invariably a main probe signal and in some cases rDNA dispersion visualised as fluorescent spots either close to the main signal or farther than the apparent dispersion centre (Fig. 5). Among distinct cell types that are present in neuroblasts, diploid nuclei displayed a single probe signal. It probably represents signals from the somatic pairing of two alleles (Fig. 6). Similar results were obtained in early (1-3 days) embryonic nuclei of Schwenkfeldina sp. (Fig. S6). It is worth mentioning hybridisation results observed in certain neuroblast nuclei 

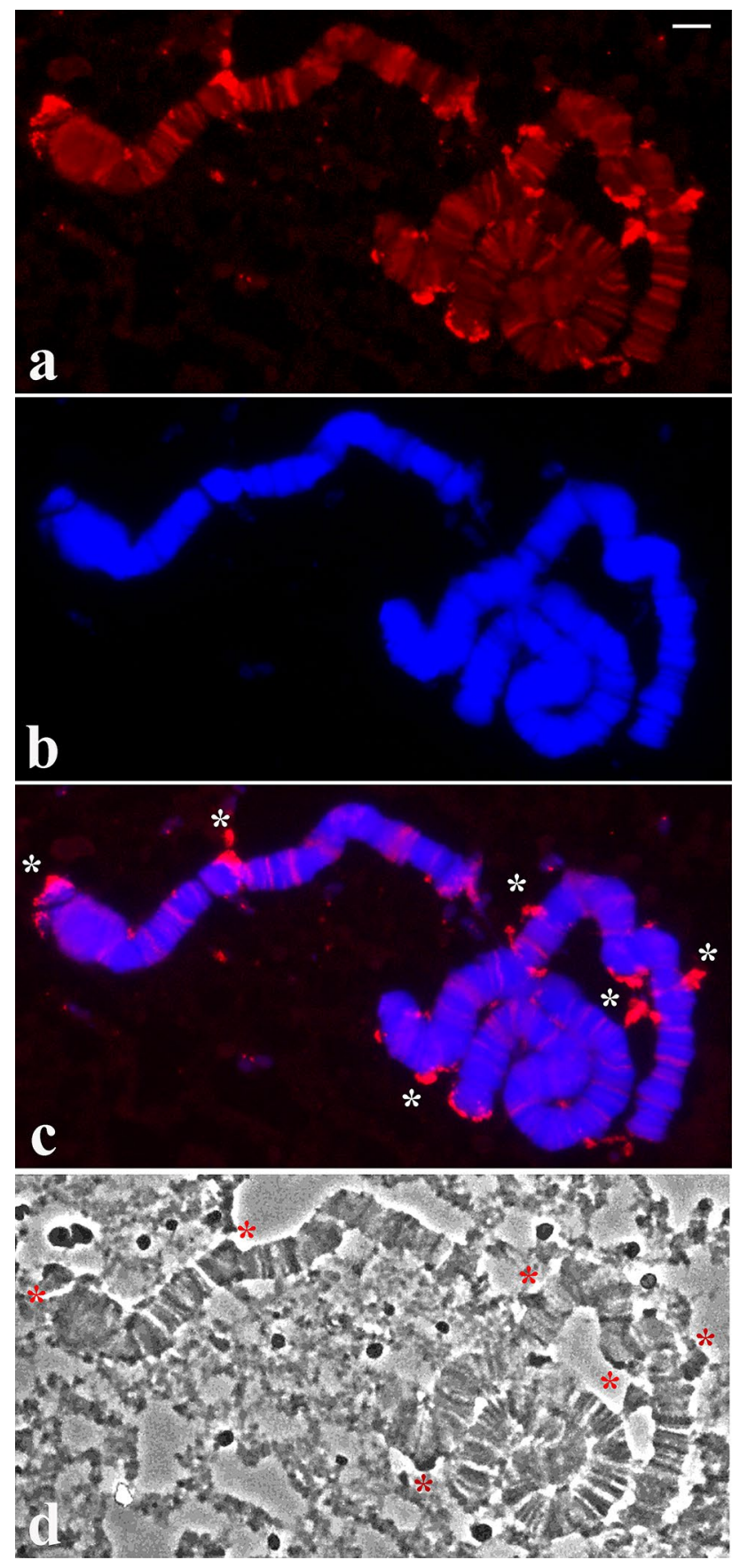

Figure 4. (a-d) Transcriptional activity in Schwenkfeldina sp. polytene chromosomes as visualised by the detection of endogenous RNA.DNA hybrids. Fluorescent antibody signals (a), the corresponding DAPI image (b), the merged signals (c) and the same chromosomes under phase contrast (d) The asterisks point to some examples in which fluorescent detection of endogenous hybrids is seen in micronucleolar bodies either disconnected or attached to the chromosomes. $\operatorname{Bar}=15 \mu \mathrm{m}$.

that underwent polyteny. These chromosomes display, in addition to the main signal, signs of rDNA dispersion (Fig. 6) such as those detected in Malpighian Tubules.

rDNA localisation in mitotic and meiotic chromosomes. The results unequivocally indicated the existence of a single rDNA locus in mitotic chromosomes Schwenkfeldina (Fig. S7a) in contrast to what is usually observed in polytene chromosomes. Examination of a number of slides indicated that rRNA genes are localised at one end of the smallest mitotic pair. No evidence for DNA complementary to ribosomal probes other than a single terminal site was found in oocyte zygotene chromosomes of Schwenkfeldina sp. (Fig. S7b). All chromosome sets showed that the rDNA terminal locus is clearly visible in the sense that it has never been linked to the $\mathrm{L}$ chromosomes, namely those that are limited to germ lines. 


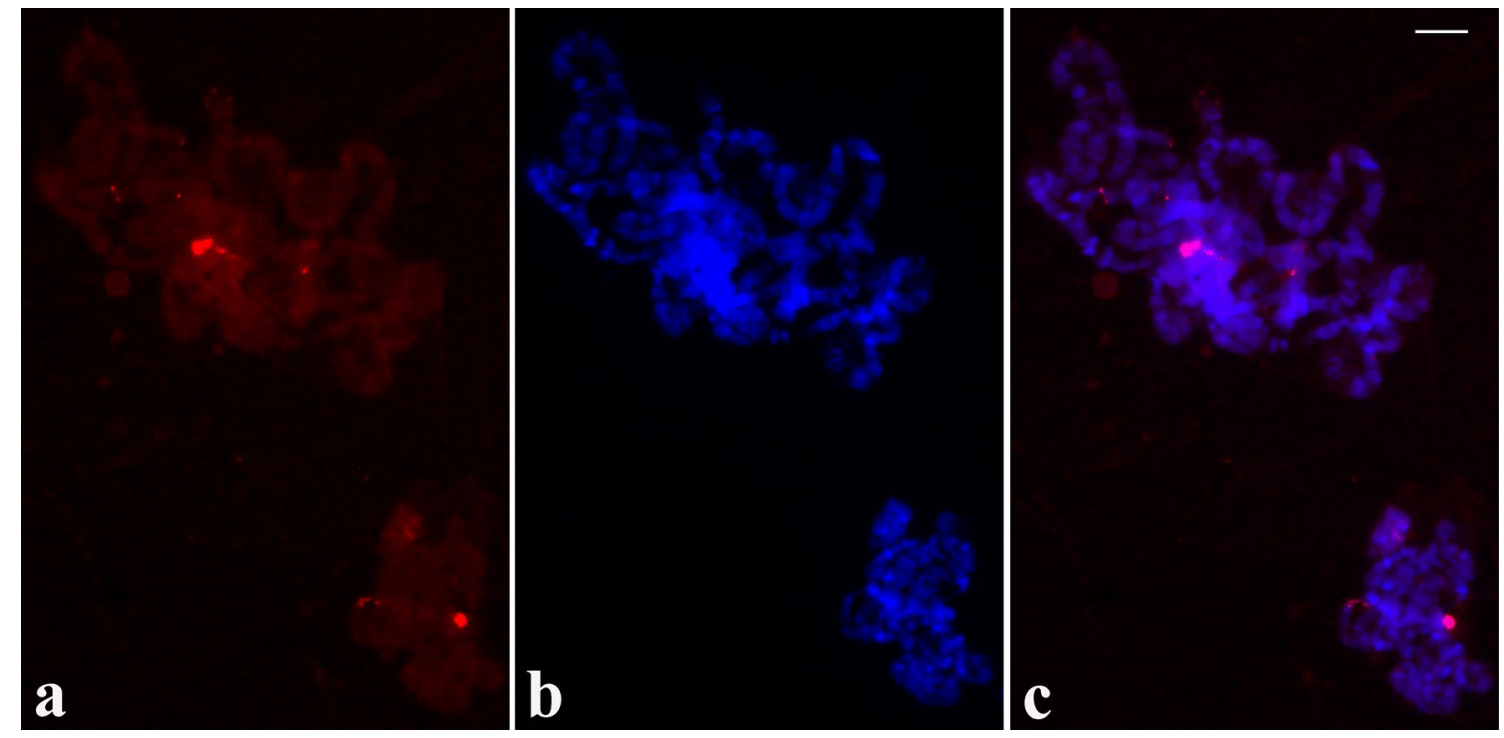

Figure 5. (a-c) Localisation of the rDNA in Schwenkfeldina sp. polytene chromosomes from Malpighian Tubules showing RNA probe signal (a), its corresponding DAPI staining image (b) and the merged signals (c). Dispersion of the rDNA in these nuclei is usually lower than that observed in posterior cells of the salivary gland. $\operatorname{Bar}=25 \mu \mathrm{m}$.
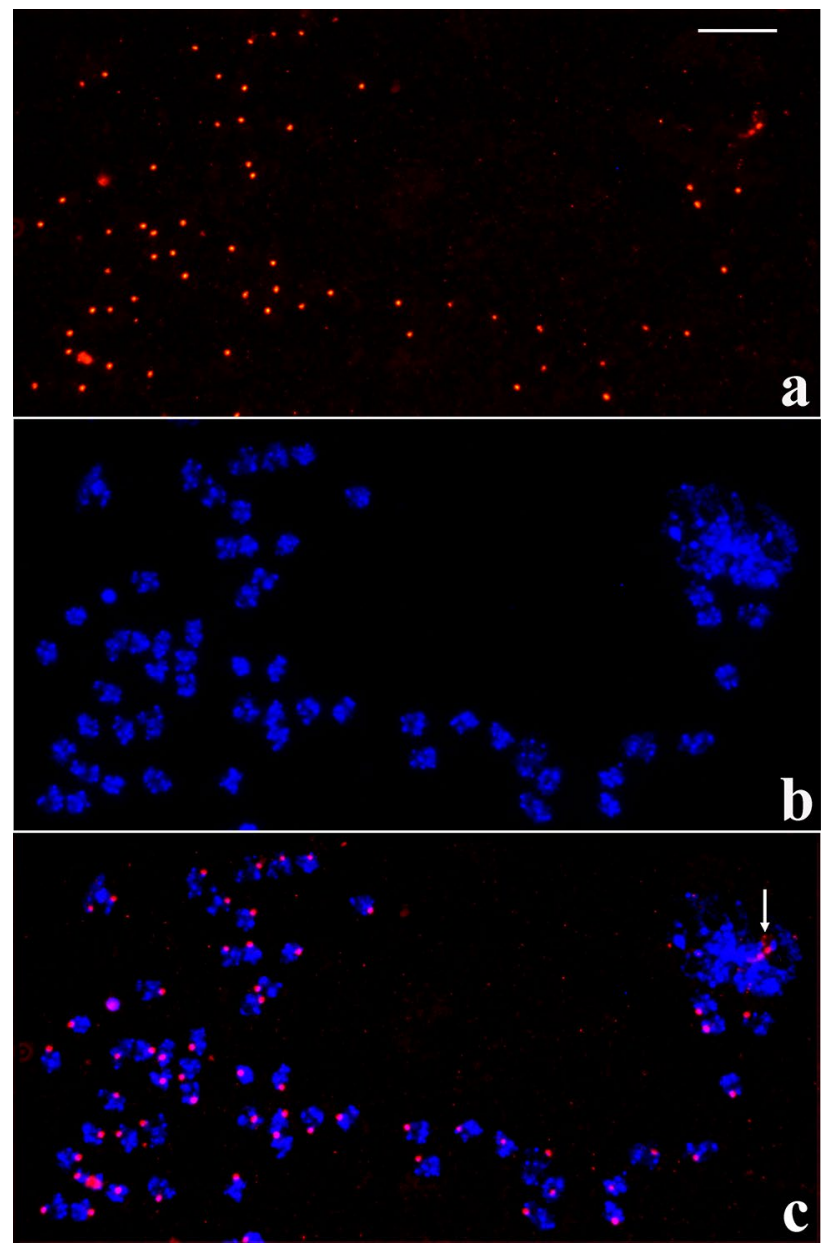

Figure 6. (a-c) Localisation of the rDNA in Schwenkfeldina sp. neuroblast nuclei showing RNA probe signals (a), its corresponding DAPI staining image (b) and the merged signals (c). Usually, a single rDNA signal is detected in diploid nuclei. The arrow points to a polytene chromosome set showing a low rDNA dispersion degree. Bar $=50 \mu \mathrm{m}$. 


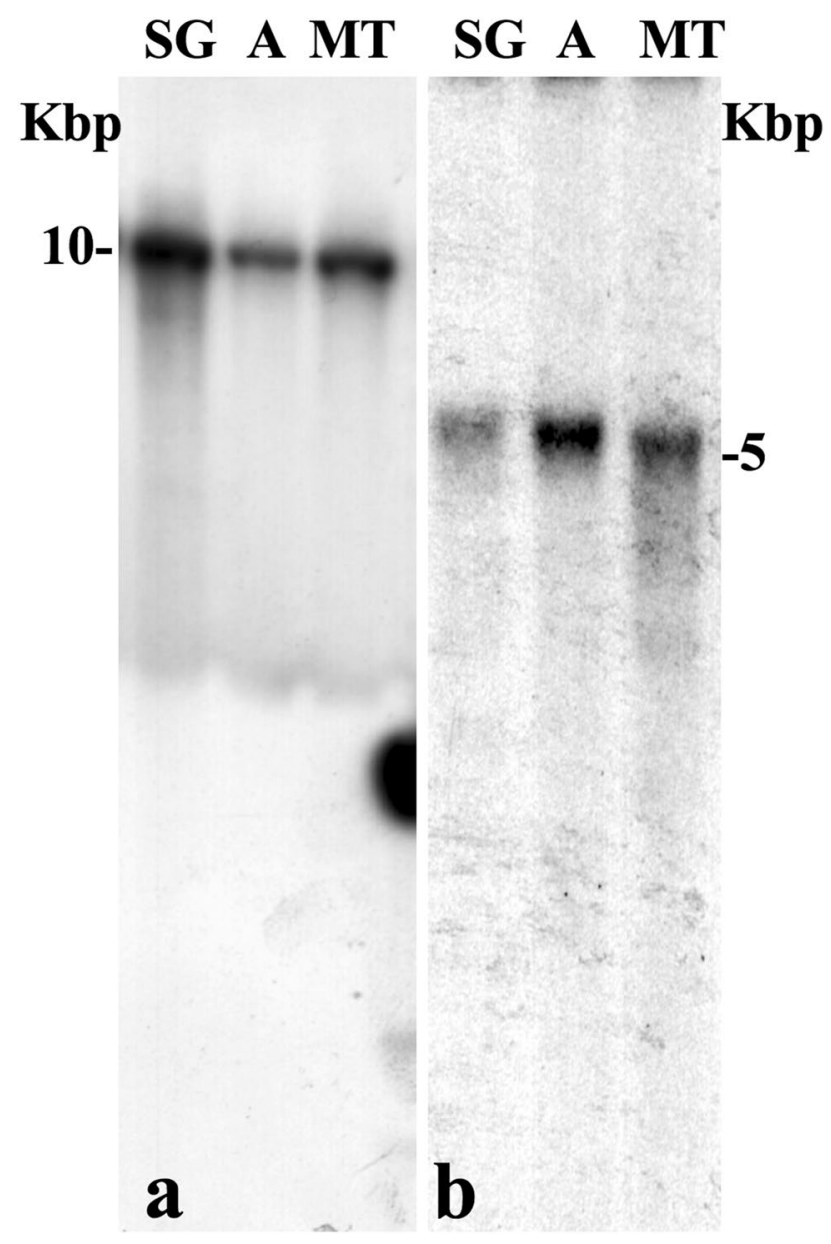

Figure 7. (a,b) Schwenkfeldina DNA from salivary gland (SG), adult flies (A) and Malpighian Tubules (TM) was cut with $E c o$ RI, electrophorised in agarose gel, transferred to the nylon membrane and hybridised to rDNA (a) and histone gene (b) probes. Size markers in Kilobase pair (Kbp).

Proportion of rDNA and histone gene copy number in polytene and diploid cells. The nucleolar fragmentation visualised as rDNA dispersion in Schwenkfeldina sp. raised the question on DNA replication and its relationship with rDNA copy number in this species. Southern-blot hybridisations were then carried out not to evaluate its rDNA absolute copy number but rather to establish a relative comparison between different cell types. Possible variations could be detected by comparing the intensity of Southern-blot hybridisation signals, with particular regard to polytene tissues relative to those that do not undergo polyteny. Quantification and sample loading were performed with extreme care to ensure that equal DNA amount from distinct cells were loaded in gels. DNA from adults was chosen as mostly representing diploid cells to be compared to those from salivary gland and Malpighian Tubules (Fig. 7a). Results obtained in three experiments showed that salivary gland lanes always displayed higher densitometric values $(1.4 \mathrm{X} \pm 0.3)$ than those measured in adult lanes, the same occurring with the lane corresponding to Malpighian Tubules $(1.2 \mathrm{X} \pm 0.2)$. Histone gene repeats were introduced in the assay as a further reference for gene copy number in diploid and polytene cells of Schwenkfeldina sp. The choice is justified by general genomic features shared by ribosomal and histone gene repeat $\mathrm{s}^{25}$ although the latter do not undergo dispersion as the rDNA of this species does. The EcoRI restriction site defines, as for the rDNA, the length of the histone repeat unit as a single band migrating with the expected size of $5 \mathrm{Kbp}$ hybridised to the probe (Fig. 7b). Results from densitometry showed that the intensity of the histone probe signal was higher in the adult lanes $(2.2 \mathrm{X} \pm 0.2 \mathrm{X})$ in three experiments performed.

Chromosomal distribution of H3K9Me in Schwenkfeldina. In polytene chromosomes of sciarid flies, heterochromatin has been identified morphologically by its condensed aspect and localisation in pericentric areas that sometimes lack the typical banding pattern of euchromatin. Heterochromatin may also appear in the form of chromosome breakpoints as a result of local DNA under-replication. As seen in R. americana, $T$. pubescens as well as in many organisms, heterochromatin is in addition characterised by the enrichment with methylation of histone $\mathrm{H} 3$ in lysine $9(\mathrm{H} 3 \mathrm{~K} 9 \mathrm{Me} 1-3)^{26,27}$. In Schwenkfeldina sp., rather than lack of banding pattern in condensed pericentric heterochromatin, its occurrence is immediately suggested by polytene chromosome breakpoints localised in several interstitial regions. Antibodies to the above mentioned epigenetic markers 
were employed to assess its distribution in polytene chromosomes. Experiments were done with either mixing antibodies to $\mathrm{H} 3 \mathrm{~K} 9 \mathrm{Me} 1-3$ or with antibodies diluted individually; the results were the same in any case. A broad distribution of the heterochromatin markers was detected throughout the polytene chromosomes with several sections displaying brighter signals (Fig. S8). Controls were done using the same antibody dilutions in polytene chromosomes of $D$. melanogaster and showed the expected results as demonstrated previously $\left({ }^{28,29}\right.$, Fig. S9). Although a chromosome map of antibody binding has not been provided, the regions stained by the antibodies coincide with those from the rDNA attachment. The results cxobtained for the first time in this species led us to investigate the chromosomal distribution of $\mathrm{H} 3 \mathrm{~K} 9 \mathrm{Me} 1-3$ and its relationship with transcriptional activity in the salivary gland. Double labelling using antibodies to H3K9Me1-3 and RNA polymerase II was then carried out. The results indicated that, although signals from the two markers overlap in some cases, most chromosome regions showed that the detection of $\mathrm{H} 3 \mathrm{~K} 9 \mathrm{Me1}-3$ and RNA polymerase II is mutually exclusive (Fig. 8).

Chromosomal distribution of rDNA and H3K9Me in $\boldsymbol{R}$. americana chromosomes. In a short report, the rDNA dispersion in the salivary gland of $R$. americana was demonstrated ${ }^{18}$. Such a process occurs regularly and results observed in polytene (Fig. S10) as well as in non-polytene chromosomes (Fig. S11) are readily reproducible in this species. In mitotic chromosomes, the NOR is located in the proximal end of the X chromosome; in zygotene chromosomes this region appeared invariably associated with L chromosomes (Fig. S11b) in contrast to the Schwenkfeldina sp. NOR (Fig. S7). Also, the polytene chromosome structure of R. americana is well defined with particular regard to the pericentric heterochromatin. These regions are distinguished by a significant enrichment with H3K9Me1-3 visualised as strong signals from the antibody binding $\left({ }^{26,27}\right.$; Fig. S12). Micronucleoli in R. americana, as seen in Schwenkfeldina sp., disperses preferentially to chromosomal regions significantly reactive to antibodies to H3K9Me1-3 (Fig. S13).

\section{Discussion}

After collecting Schwenkfeldina for the first time, early cytological observations already indicated its unusual nucleolar structure in the salivary gland. In relation to data obtained in S. coprophila, T. pubescens, Rhynchosciara species, Sciara pauciset $a^{30}$ and Sciara ocellaris ${ }^{31}$, Schwenkfeldina sp. represents the most extreme case of nucleolar/ rDNA dispersion. The results presented in this work have been exhaustively reproduced in the laboratory with different larval groups of this species since the first in situ hybridisation experiments.

The localisation of the rDNA in polytene chromosomes of Schwenkfeldina sp. is due to the attachment of micronucleoli originating from a single locus, as observed after hybridisation results in mitotic chromosomes where the NOR is located at one end of the smallest chromosome pair which is not the X according to the sciarid chromosome nomenclature ${ }^{2}$. This question could be resolved in this work by performing in situ hybridisation in male mitotic chromosomes (sex-determination system X0) that have not been available. Unless this species has an exceptionally short X chromosome, the data imply the existence of sciarid species with rDNA loci in chromosome $\mathrm{C}$ rather than the sex chromosome. Support for such a possibility also comes from other sciarid, Bradysia hygida, whose NOR is localised at the pericentric end of chromosome $\mathrm{C}^{32}$.

The rDNA dispersed is contained in multiple ectopic nucleoli of Schwenkfeldina sp. Such micronucleolar regions could be called "extra-chromosomal loci" since integration of dispersed rDNA into the chromosome structure is unlikely. Support for the latter assumption comes from data indicating that a significant amount of rDNA is not integrated to the polytene chromosome structure of $S$. coprophila ${ }^{33}$. Since hybridisation occurred regularly to several chromosome regions of Schwenkfeldina sp. and also to chromosome sections C-11, B-15, X-1 and B-13 of R. americana, the "extra-chromosomal rDNA loci" cannot be explained as a random adherence of micronucleoli to these regions.

Among the processes that lead to nucleolar fragmentation and concomitant rDNA dispersion, DNA replication cycles for polytenisation seems to be one of these requirements. Support for this idea comes from the detection of rDNA dispersion restricted to nuclei undergoing polyteny. However, additional partners that are still unknown are involved in the control of this process, an assumption justified by the following examples. The extent of rDNA dispersion seemed to be a function of the number of DNA replication cycles (Figs. 3, 4); on the other hand, chromosomes displaying comparatively lower polyteny degree may present significant nucleolar fragmentation (Fig. 5). A further example showed rather a low degree of rDNA dispersion in nuclei that underwent low polytenisation (Fig. 6). The data suggest that nucleolar/rDNA dispersion in the salivary gland is differentially controlled depending on the cell type.

Southern-blot hybridisation data indicated that the proportion of rDNA in the two polytene tissues of Schwenkfeldina sp. is higher than in adults, the later assumed to represent diploid cells. These results were unexpected since in $R$. americana the rDNA was reported have approximately half of copy number for salivary gland in relation to the ovary ${ }^{34,35}$. As the reference for diploid tissues used in this work was adult flies rather than ovary, this might explain the discrepancy between the two reports. In contrast, histone genes are under-replicated in polytene tissues compared to adult cells in all the experiments done. Under-replication of sequences located in the heterochromatin is generally due to their delayed replication compared with the bulk of euchromatic DNA as early observed in Drosophila ${ }^{36,37}$. All the sciarid species that have been studied to date have NORs in the heterochromatin (see references in Introduction) so that rDNA under-replication is expected. Numeric values for the rDNA in polytene cells of Schwenkfeldina sp., albeit higher, are not very far from those measured for adults. For this reason, rDNA amplification, as historically detected in amphibian oocytes ${ }^{38}$, may not be the exact definition for this finding. In this sense, it is worth mentioning that dispersed nucleolar material in Sciara raised the hypothesis on the extra-chromosomal rDNA generation as a device to restore the rDNA content in salivary gland nuclei $^{33}$. Multiple nucleoli in Schwenkfeldina sp. together with the lack of rDNA under-replication in polytene 

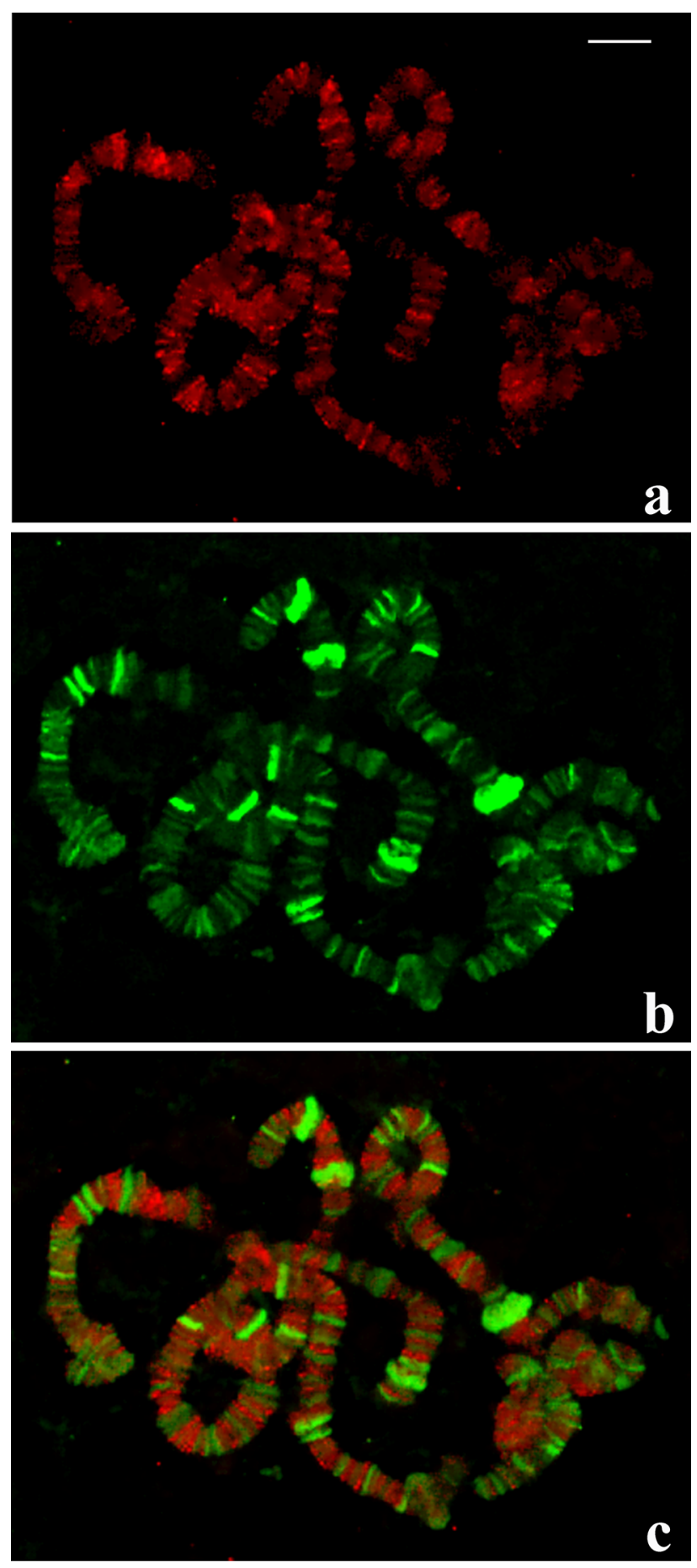

Figure 8. (a-c) Distribution of H3K9Me1-3 and RNA polymerase II in Schwenkfeldina sp. polytene chromosomes. Anti-H3K9Me1-3 labelling (a), anti-RNA polymerase II labelling (b) and the merged signals (c). Visualisation of signals from the two markers indicates that both do not usually overlap. Bar $=30 \mu \mathrm{m}$.

nuclei is likely to play a role in order to counterbalance the rDNA loss that occurs in polytene cells due to the chromatin under-replication as suggested by previous data and reinforced by the results obtained in this work.

The chromosomal location of $\mathrm{H} 3 \mathrm{~K} 9 \mathrm{Me} 1-3$, unusual at a first glance, agreed with early cytological findings. Several interstitial breakpoints in chromosomes of Schwenkfeldina sp. suggested that heterochromatic regions were spread throughout the chromosome length. Also, the distribution of H3K9Me1-3, the most conserved epigenetic marker for the heterochromatin, relative to RNA polymerase II may be viewed as an expected result regarding, if any, low transcriptional activity at those sites where H3K9Me1-3 was detected. As the extra-chromosomal rDNA within micronucleoli is usually associated or close to the regions defined epigenetically as heterochromatin, it must play a role in order to establish the rDNA topology in sciarid polytene nuclei. Such an 
assumption is supported by R. americana data showing that the distribution of extra-chromosomal DNA follows the location of regions that are distinguished by the enrichment with H3K9Me1-3.

The nucleolar scenario in Schwenkfeldina sp. salivary gland resembles to some extent that reported for the salivary gland chromosomes of Pseudodiamesa branickii (Diptera: Chironomidae). Chromosome 4 of this species carries the NOR and DNA under-replication impedes its complete polyteny so that only three chromosomes are seen in salivary gland nuclei. Selective polytenisation leads to rDNA replication forming multiple nucleoli associated to many polytene regions of the three Pseudodiamesa polytene chromosomes ${ }^{39}$. The intriguing nucleolar picture in the chironomid salivary gland is morphologically reminiscent of nucleolar dispersion detected in Schwenkfeldina sp. Whether it implies either under-replication or amplification processes has remained speculative.

Hybridisation experiments have not been performed with the chromosomes of the sciarid Hybosciara fragilis, as it has not yet been re-collected. This species is likely to fall in the Schwenkfeldina group since nucleolar-like bodies in Hybosciara displayed a chromosomal distribution resembling that observed in Schwenkfeldina. The morphological aspect of those structures suggests that they are indeed nucleolar organisers attached to the chromosomes ${ }^{10}$. In summary, rDNA dispersion in Schwenkfeldina sp. probaly represents, rather than an exception, a dramatic example of a process that occurs in sciarid cells undergoing polyteny. Further functional implications from the preference of dispersed rDNA for the heterochromatin in Schwenkfeldina, Rhynchosciara and other members of Sciaridae cannot be explained at present and remains to be investigated.

\section{Methods}

Animals. Schwenkfeldina sp. adults were collected on the campus of the University of São Paulo (we thank Dr. D. S. Amorim for identification of the genus). Larvae were kept in the laboratory at $18{ }^{\circ} \mathrm{C}$ and food consisted of fresh Sterculia chicha flowers squashed in water. Rhynchosciara americana larval groups were collected in private banana plantations in the region of Mongaguá, São Paulo. Larvae were kept in the laboratory at $18{ }^{\circ} \mathrm{C}$ and food consisted of fresh potato leaves. Drosophila melanogaster wild type (Oregon R) came from laboratory stocks.

Preparation of chromosome and embryonic nuclei spreads. Salivary glands and Malpighian Tubules were dissected in 1X PBS and fixed briefly in ethanol-acetic acid (3:1). After squashing the glands in $50 \%$ acetic acid, the slides were frozen in liquid nitrogen. The coverslips were flipped off with a razor blade and the slides were then kept in absolute ethanol at $-20^{\circ} \mathrm{C}$. Preparation of chromosome spreads from dissected brain ganglia and ovarian follicle cells was carried out as described ${ }^{40}$ and the slides stored as above. Embryos were immersed in $2.5 \%$ sodium hypochlorite for $5 \mathrm{~min}$, washed in $1 \mathrm{X}$ PBS, $0.1 \%$ Tween 20 . After keeping the embryos in heptane for $10 \mathrm{~min}$, fixation was made with $70 \%$ ethanol and the squashes were done in $50 \%$ acetic acid following additional procedures as described above. For chromosomal protein detection, salivary glands were squashed in a solution containing $3.7 \%$ formaldehyde, $40 \%$ acetic acid following the same procedures as described above.

Preparation of the probes. A sub-clone containing the complete rDNA repeat unit of $R$. americana named $\mathrm{p} R a-1.4^{41}$ was used as rDNA probe. Plasmid DNA extraction was done according to current protocols (Life Tech) and labelled by nick translation with either biotin or digoxigenin following the instruction of the manufacturer (Roche). An alternative RNA probe was prepared with insect total RNA extraction (TRIzol, Life Tech) dissolved in formamide containing an excess of poly ( $r)-U$ (Roche). Total RNA is predominantly composed of rRNA but messenger poly-(r)A tails are present and are apt to hybridise to poly (d)A.(d)T-rich chromosomal regions ${ }^{24}$. This has to be avoided, particularly for Rhynchosciara species, if the detection is carried out with the anti-RNA.DNA hybrid antibody. Poly ( $r)-U$ in the hybridisation mixture will form complexes with poly (r)-A tails, preventing them from hybridising to homopolymer-rich chromosomal DNA ${ }^{42}$. Use of the rRNA probe made as described above reproduced the same hybridisation results observed with rDNA probes.

In situ hybridisation. When the RNA probe was used, the air-dried chromosome squashes were treated with RNase A $(0.6 \mathrm{mg} / \mathrm{ml})$ diluted in $2 \mathrm{X} \mathrm{SSC}$ at $37^{\circ} \mathrm{C}$ for at least $2 \mathrm{~h}$ in a moist chamber. The probe mixtures consisted of $50 \%$ formamide, 2 X SSPE, $0.1 \%$ SDS, $30 \mathrm{ng} / \mu \mathrm{l}$ labelled DNA or $200 \mathrm{ng} / \mu \mathrm{l}$ insect RNA mixed with poly (r)-U. Six $\mu$ l of probe mixture was applied to each air-dried slide and covered with a plastic coverslip. Metaphase and polytene chromosome slides were steam heated at $75^{\circ} \mathrm{C}$ for $10 \mathrm{~min}$ to denature both chromosomal DNA and probe, and then kept in a closed box at $37^{\circ} \mathrm{C}$ overnight (up to $48 \mathrm{~h}$ for metaphase chromosomes) for hybridisation. When DNA probes were used, chromosome squashes were treated with RNase A $(0.6 \mathrm{mg} /$ $\mathrm{ml}$ ) diluted in $2 \mathrm{X} \mathrm{SSC}$ at $37^{\circ} \mathrm{C}$ for at least $2 \mathrm{~h}$ in a moist chamber. Hybridization procedures and detection of DNA labelled probes were described elsewhere ${ }^{17-20}$. When the RNA probe was used, the slides were washed twice in $0.1 \mathrm{X}$ SSPE, $0.1 \%$ SDS at $37^{\circ} \mathrm{C}$, followed by incubation at room temperature in $1 \mathrm{X}$ TBS, $0.1 \%$ Triton X-100 (TBST), 10\% Superblock (Pierce) for $30 \mathrm{~min}$. The slides were incubated with goat IgG anti-RNA.DNA hybrid $^{22}$ diluted 1:50 in TBST/Superblock solution. After $1 \mathrm{~h}$ at room temperature in a moistened chamber, the slides were washed twice in TBST for $30 \mathrm{~min}$ and then incubated with rabbit IgG anti-goat labelled with TRITC (Sigma) diluted 1:200 as described above. The slides were washed twice in TBST for $30 \mathrm{~min}$ and finally once in 1X TBS for $5 \mathrm{~min}$. Chromosomes were stained with 4', 6-diamidino-2-phenylindole (DAPI). The slides were mounted in antifading medium (Vectashield, Vector Labs) and inspected with epifluorescence optics (Nikon).

Endogenous hybridisation. Formation of endogenous RNA.DNA hybrids was performed by fixing salivary glands in ethanol-acetic acid (3:1) and squashing in 50\% acetic acid, following the same steps described for 
preparation of chromosome spreads. The slides that were kept frozen in ethanol were hydrated in $1 \mathrm{X}$ TBS and subsequently incubated in $50 \%$ acetic acid at $42{ }^{\circ} \mathrm{C}$ for $2-5 \mathrm{~min}$. Detection of endogenous RNA.DNA hybrid, control with RNases and mounting of the slides were done as described for in situ hybridisation with RNA probe.

Immunolabelling. The slides were rehydrated in $1 \mathrm{X}$ TBS followed by incubation at room temperature in TBST, 10\% Superblock (Pierce) for $20 \mathrm{~min}$. Monoclonal antibodies to RNA polymerase II (Upstate Tech, clone CTD4H8) as well as polyclonal antibodies to the three methylation forms of histone $\mathrm{H} 3$ in lysine 9 (Upstate Tech 07-440, 07-441, 07-442) were diluted 1:100 in TBST/Superblock solution. The incubations were done in a moistened chamber at room temperature for $2 \mathrm{~h}$. After washes in TBST, the slides were incubated for $1 \mathrm{~h}$ at room temperature with a mixture containing goat IgG anti-rabbit IgG conjugated with TRITC (Sigma) and goat IgG anti-mouse conjugated with Alexa Fluor 488 (Molecular Probes), both diluted 1:200 in TBST. The slides were washed twice in TBST for $30 \mathrm{~min}$ and finally in $1 \mathrm{X}$ TBS for $5 \mathrm{~min}$. Chromosomes were stained with $4^{\prime}$, 6-diamidino-2-phenylindole (DAPI). The slides were mounted in antifading medium (Vectashield, Vector Labs) and inspected with epifluorescence optics (Nikon).

Southern blot hybridisation. DNA extraction was carried out according to standard protocols ${ }^{43}$. DNA samples (5-7 $\mu \mathrm{g}$ of each sample per lane) were quantified by spectrophotometry (NanoDrop ND-100, Uniscience) three times prior to digestion with EcoRI. Restriction enzymes and DNA size markers were purchased from New England Biolabs. DNA from gels was alkaline transferred to Hybond $\mathrm{N}+$ membranes according to standard procedures (GE Healthcare). Three hybridisation assays were carried out overnight at $60{ }^{\circ} \mathrm{C}$ in $0.5 \mathrm{M} \mathrm{Na}_{2} \mathrm{HPO}_{4}, 2 \% \mathrm{SDS}_{\text {. Ribosomal DNA }}^{41}$ and histone gene ${ }^{44}$ inserts were labelled by random priming with ${ }^{a 32} \mathrm{P}$-dATP following current protocols (Life Tech). The membranes were washed twice at $60{ }^{\circ} \mathrm{C}$ for $30 \mathrm{~min}$ in $40 \mathrm{mM} \mathrm{Na} \mathrm{HPO}_{4}, 2 \% \mathrm{SDS}$. Signal quantification was performed with ImageJ $1.48 \mathrm{~V}$ Analysis Software (Wayne Rasband, NIH, USA).

Received: 28 October 2020; Accepted: 24 February 2021

Published online: 16 April 2021

\section{References}

1. Stormo, B. M. \& Fox, D. T. Polyteny: still a giant player in chromosome research. Chromosome Res. 25, 201-214 (2017).

2. Metz, C. W. \& Gay, E. H. Chromosomes structure in the salivary gland of Sciara. Science 80, 595-596 (1934).

3. Poulson, D. F. \& Metz, C. W. Studies on the structure of nucleolus-forming regions and related structures in the giant salivary gland chromosomes of Diptera. J. Morph. 63, 363-395 (1938).

4. Breuer, M. E. \& Pavan, C. Behavior of polytene chromosomes of Rhynchosciara angelae at different stages of larval development. Chromosoma 7, 371-386 (1955).

5. Gabrusewycz-Garcia, N. \& Kleinfeld, R. G. A study of the nucleolar material in Sciara coprophila. J. Cell Biol. 29, 347-359 (1966).

6. Mattingly, E. \& Parker, C. Sequence of puff formation in Rhynchosciarapolytene chromosomes. Chromosoma 23, 255-270 (1968).

7. Perrin, L. et al. Dynamics of the sub-nuclear distribution of Modulo and the regulation of position-effect variegation buy nucleolus in Drosophila. J. Cell Sci. 111, 2753-2761 (1998).

8. Sun, X. et al. A novel protein localized to the fibrillar compartment of the nucleolus and the brush border of a secretory cell. Eur. J. Cell Biol. 8, 125-137 (2002).

9. Pavan, C. Nucleic acid metabolism in polytene chromosomes and the problem of differentiation. Brookhaven Symp. Biol. 18, 222-241 (1965).

10. Da Cunha, A. B., Pavan, C., Morgante, J. S. \& Garrido, M. C. Studies on cytology and differentiation in Sciaridae. II. DNA redundancy in salivary gland cells of Hybosciara fragilis (Diptera, Sciaridae). Genetics 61(suppl), 335-349 (1969).

11. Gabrusewycz-Garcia, N. Further studies of the nucleolar material in salivary gland nuclei of Sciara coprophila. Chromosoma 38, 237-254 (1972).

12. Pardue, M. L., Gerbi, S. A., Eckardt, R. A. \& Gall, J. G. Cytological localization of the DNA complementary to ribosomal RNA in polytene chromosomes of Diptera. Chromosoma 29, 268-290 (1970).

13. Gerbi, S. A. Localization and characterization of the ribosomal RNA cistrons of Sciara coprophila (Diptera). J. Mol. Biol. 58, 499-511 (1971).

14. Gerbi, S. A. \& Crouse, H. V. Further studies on the ribosomal cistrons of Sciara coprophila (Diptera). Genetics 83, 81-90 (1976).

15. Crouse, H. V., Gerbi, S. A., Liang, C. M., Magnus, L. \& Mercer, I. M. Localization of ribosomal DNA within the proximal X heterochromatin of Sciara coprophila (Diptera: Sciaridae). Chromosoma 64, 305-318 (1977).

16. Pardue, M. L. \& Gall, J. G. In Molecular cytogenetics (ed. Sussman, M.) 65-99 (Prentice-Hall, 1973).

17. Stocker, A. J., Gorab, E., Amabis, J. M. \& Lara, F. J. S. A molecular cytogenetic comparison between Rhynchosciara americana and Rhynchosciara hollaenderi (Diptera: Sciaridae). Genome 36, 831-843 (1993).

18. Madalena, C. R. G., Amabis, J. M., Stocker, A. J. \& Gorab, E. The localization of ribosomal DNA in Sciaridae (Diptera: Nematocera) reassessed. Chromosome Res. 15, 409-416 (2007).

19. Madalena, C. R. G., Andrioli, L. P. M. \& Gorab, E. Ribosomal RNA gene insertions in the R2 site of Rhynchosciara. Chromosome Res. 16, 1233-1241 (2008).

20. Stocker, A. J. \& Gorab, E. The chromosomes of Rhynchosciara baschanti (Diptera: Sciaridae): molecular cytogenetic comparisons with taxa in the americana-like group. Genome 43, 786-795 (2000).

21. Amabis, J. M. The polytene chromosomes of the salivary gland of Trichosia pubescens. Genet. Mol. Biol. 6, 415-424 (1983).

22. Kitagawa, Y. \& Stollar, B. D. Comparison of poly (A).poly (dT) and poly (A).poly (dC) as immunogens of the induction of antibodies to RNA.DNA hybrids. Mol. Immunol. 19, 413-420 (1982).

23. Büsen, W., Amabis, J. M., Leoncini, O., Stollar, B. D. \& Lara, F. J. S. Immunofluorescent characterization of DNA.RNA hybrids on polytene chromosomes of Trichosia pubescens (Diptera: Sciaridae). Chromosoma 87, 247-262 (1982).

24. Gorab, E., Amabis, J. M., Stocker, A. J., Drummond, L. \& Stollar, B. D. Potential sites of triple helical nucleic acid formation in chromosomes of Rhynchosciara americana (Diptera: Sciaridae) and Drosophila melanogaster. Chromosome Res. 17, 821-832 (2009).

25. Roehrdanz, R., Heilmann, L., Senechal, P., Sears, S. \& Evenson, P. Histone and ribosomal RNA repetitive gene clusters of the boll weevil are linked in a tandem array. Insect Mol. Biol. 19, 463-471 (2010). 
26. Madalena, C. R. G., Díez, J. L. \& Gorab, E. Chromatin structure of ribosomal RNA genes in dipterans and its relationship to the location of nucleolar organizers. PLoS ONE 7, e44006. https://doi.org/10.1371/journalpone0044006 (2012).

27. Badaracco, A. \& Gorab, E. Unusual chromatin state in Rhynchosciara americana (Diptera: Sciaridae). Chromosome Res. 23, 781-790 (2015).

28. Ebert, A., Lein, S., Schotta, G. \& Reuter, G. Histone modification and the control of heterochromatic gene silencing in Drosophila. Chromosome Res. 14, 377-392 (2006).

29. Eissenberg, J. C. \& Shilatifard, A. Leaving a mark: the many footprints of the elongating RNA polymerase II. Curr. Opin. Genet. Dev. 16, 184-190 (2006)

30. Gabrusewycz-Garcia, N. Studies in the polytene chromosomes of sciarids 1. The salivary glands of Sciara (Lycoriella) pauciseta (II), Felt. Chromosoma 33, 421-435 (1971).

31. Dessen, E. M. B. \& Perondini, A. L. P. Nucleolar sub-units in the salivary gland nuclei of Sciara ocellaris. Genet. Mol. Biol. 14, 1-11 (1991).

32. Gaspar, V. P., Shimauti, E. L. \& Fernandez, M. A. Chromosomal localization and partial sequencing of the $18 \mathrm{~S}$ and $28 \mathrm{~S}$ ribosomal genes from Bradysia hygida (Diptera: Sciaridae). Genet. Mol. Res. 13, 2177-2185 (2014).

33. De Lucchini, S., Gerbi, S. A. \& Carri, M. T. Extrachromosomal ribosomal DNA in polytene nuclei of Sciara coprophila. J. Cell Biol. 95, 212 (1982).

34. Gambarini, A. G. \& Meneghini, R. Ribosomal RNA genes in salivary gland and ovary of Rhynchosciara angelae. J. Cell Biol. 5, 421-426 (1972).

35. Gambarini, A. G. \& Lara, F. J. S. Under-replication of ribosomal cistrons in polytene chromosomes of Rhynchosciara. J. Cell Biol. 62, 215-222 (1974).

36. Hennig, W. \& Meer, B. Reduced polyteny of ribosomal RNA cistrons in giant chromosomes of Drosophila hydei. Nat. New Biol. 233, 70-72 (1971).

37. Spear, B. B. \& Gall, J. G. Independent control of ribosomal gene replication in polytene chromosomes of Drosophila melanogaster. Proc. Natl. Acad. Sci. USA 70, 1359-1363 (1973).

38. Brown, D. D. \& Dawid, I. B. Specific gene amplification in oocytes. Oocyte nuclei contain extrachromosomal replicas of the genes for ribosomal RNA. Science 160, 272-280 (1968).

39. Zacharias, H. Allocyclicbehaviour and under-replication of the nucleolus chromosome in Pseudodiamesa (Chironomidae). Chromosoma 89, 263-273 (1984).

40. Ashburner, M. Drosophila: a laboratory handbook (Cold Spring Harbor Laboratory Press, 1989).

41. Zaha, A., Leoncini, O., Hollenberg, C. P. \& Lara, F. J. S. Cloning and characterization of the ribosomal RNA genes of Rhynchosciara americana. Chromosoma 87, 103-116 (1982).

42. Stocker, A. J. \& Gorab, E. Local enrichment with homopolymeric (dA/dT) DNA in genomes of some lower dipterans and Drosophila melanogaster. Chromosoma 111, 455-460 (2003).

43. Sambrook, J., Fritsch, E. F. \& Maniatis, T. Molecular cloning: a laboratory manual (Cold Spring Harbor Laboratory Press, 1989).

44. Hankeln, T. \& Schmidt, E. R. The organization, localization and nucleotide sequence of the histone genes of the midge Chironomus thummi. Chromosoma 101, 25-31 (1991).

45. Breuer, M. E. Cromossomospolitênicos das glândulassalivares de Rhynchosciara angelae (Diptera: Sciaridae). Rev. Bras. Biol. 27, 105-108 (1967).

\section{Acknowledgements}

The authors thank Dr. B.D. Stollar for providing us with anti-hybrid antibody, A.Y. Silvestre and M.E. Cesário for technical assistance and F. Flausino and C. Lopes for maintenance of Drosophila stocks. This research was funded by Fundação de Amparo à Pesquisa do Estado de São Paulo (FAPESP), Grant 2017/02588-6.

\section{Author contributions}

J.M.A. made figures, E.G. made figures and wrote the manuscript. All authors reviewed the manuscript.

\section{Competing interests}

The authors declare no competing interests.

\section{Additional information}

Supplementary Information The online version contains supplementary material available at https://doi.org/ 10.1038/s41598-021-87012-5.

Correspondence and requests for materials should be addressed to E.G.

Reprints and permissions information is available at www.nature.com/reprints.

Publisher's note Springer Nature remains neutral with regard to jurisdictional claims in published maps and institutional affiliations.

Open Access This article is licensed under a Creative Commons Attribution 4.0 International License, which permits use, sharing, adaptation, distribution and reproduction in any medium or format, as long as you give appropriate credit to the original author(s) and the source, provide a link to the Creative Commons licence, and indicate if changes were made. The images or other third party material in this article are included in the article's Creative Commons licence, unless indicated otherwise in a credit line to the material. If material is not included in the article's Creative Commons licence and your intended use is not permitted by statutory regulation or exceeds the permitted use, you will need to obtain permission directly from the copyright holder. To view a copy of this licence, visit http://creativecommons.org/licenses/by/4.0/.

(c) The Author(s) 2021 